Check for updates

Cite this: RSC Adv., 2019, 9, 20670

\title{
Effect of counter-ions on the properties and performance of non-conjugated polyelectrolyte interlayers in solar cell and transistor devices $\uparrow$
}

\author{
Ju Hwan Kang, (D) a Yu Jung Park, ${ }^{a}$ Myung Joo Cha, ${ }^{a}$ Yeonjin Yi, ${ }^{b}$ Aeran Song, ${ }^{c}$ \\ Kwun-Bum Chung, (D) Jung Hwa Seo (D) ${ }^{\text {*a }}$ and Bright Walker (iD)*d
}

\begin{abstract}
We have investigated a series of non-conjugated polyelectrolytes (NPEs) which are based on a polyethylenimine (PEI) backbone with various counterions, such as $\mathrm{Br}^{-} \mathrm{I}^{-}$and $\mathrm{Blm}_{4}^{-}$, as interfacial layers at the electrodes of solar cells and transistor devices to improve the power conversion efficiency (PCE) and device performance. This new series of NPEs with different counterions are capable of forming electric dipoles at NPE/metal electrode interfaces; as a consequence tuning of the energy levels, and work function (WF) of the electrodes is possible. Using this approach, the PCE of organic solar cells could be improved from 1.05\% (without NPEs) to 6.77\% (with NPEs) while the charge carrier mobility and on/off ratio of FET devices could be improved, showing the broad utility of this type of material. This study provides a novel approach towards investigating the influence of ions on interfacial dipoles and electrode WFs in solution-processed semiconducting devices.
\end{abstract}

Received 7th June 2019

Accepted 16th June 2019

DOI: $10.1039 / \mathrm{c} 9 \mathrm{ra04299g}$

rsc.li/rsc-advances

separation morphology via diversified strategies, have

\section{Introduction}

Bulk heterojunction (BHJ) organic solar cells (OSCs), which consist of conjugated polymers and a fullerene acceptor may be regarded as next-generation solar cells due to their advantages such as cost-efficiency, printability, light weight, flexibility, semitransparency and the potential for large area fabrication at low cost. ${ }^{1-4}$ The most important advantage of OSCs is their solution processability, which enables mass production through economical and large-scale processing technologies such as roll-to-roll manufacturing..$^{5-7}$

However, in order to be commercially successful or practical in terms of compatibility with low-cost manufacturing technologies, power conversion efficiencies (PCEs) must be comparable to those of silicon solar cells. Extensive research relating to the development of novel donor and acceptor materials, interfacial materials for better charge-carrier collection, morphology control and processing additives, phase-

${ }^{a}$ Department of Materials Physics, Dong-A University, 49315, Republic of Korea. E-mail:seojh@dau.ac.kr

${ }^{b}$ Institute of Physics and Applied Physics, Yonsei University, Seoul 03722, Republic of Korea

${ }^{c}$ Division of Physics and Semiconductor Science, Dongguk University, Seoul, 04620, Republic of Korea

${ }^{d}$ Department of Chemistry, Kyung Hee University, 02453, Seoul, Republic of Korea. E-mail: walker@khu.ac.kr

$\dagger$ Electronic supplementary information (ESI) available: Synthesis of NPEs, device data for P3HT : PC61BM solar cells, output characteristics of IZO FETs, Au $4 \mathrm{f}$ XPS spectra, AFM images and water contact angle measurements of NPE films. See DOI: $10.1039 / \mathrm{c} 9 \mathrm{ra} 04299 \mathrm{~g}$ improved PCEs up to $15 \% .^{8-18}$

In order for charges to be extracted efficiently, interfacial materials that minimize energy barriers between semiconducting layers and electrodes are necessary. In this context, organic molecules as well as metal oxides can be used. Currently, the most commonly used oxides include $\mathrm{TiO}_{2}$, and $\mathrm{ZnO}$; alkali metal compounds, such as $\mathrm{Cs}_{2} \mathrm{CO}_{3}$, may also be used to control the interfacial properties of junctions formed between electrodes and the photoactive layer. ${ }^{19-22}$ These inorganic oxides are considered to be excellent interfacial materials due to their superior stability and electrical properties. These interfacial materials facilitate the extraction of n-type charge carriers from the active layer and act as effective cathode interlayers. Interestingly, oxides like $\mathrm{TiO}_{2}$ recently can be used in combination with other materials as well. ${ }^{23} \mathrm{Sn}$ doping of the $\mathrm{TiO}_{2}$ layer has been observed to improve diode characteristics and overall solar cell performance; the PCE of the inverted PTB7-based devices increased from $6.7 \%$ to $7.6 \%{ }^{24}$

$\mathrm{ZnO}$ is a semiconducting oxide which has also been used extensively as an electron transport layer (ETLs). In the case of inverted organic solar cells (IOSCs), interfacial ZnO layers deposited on ITO electrodes are designed to reduce ohmic loss which occur during movement of electrons from the active layer to the electrode by adjusting the conduction band energy near the electrode to match that of the photoactive layer. Lim and coworkers developed a ZnO layer with a rippled texture, which was improved significantly when an additional [6,6]-phenyl $\mathrm{C}_{61}$ butyric acid methyl ester $\left(\mathrm{PC}_{61} \mathrm{BM}\right)$ layer was inserted between the $\mathrm{ZnO}$ layer and active layer. Using a PTB7-derived copolymer blended with 
[6,6]-phenyl $\mathrm{C}_{71}$ butyric acid methyl ester $\left(\mathrm{PC}_{71} \mathrm{BM}\right)$ as the active layer in inverted devices, a PCE of up to $7.7 \%$ was achieved. ${ }^{25}$

Conjugated polyelectrolytes (CPEs) are one of the most widely used ETLs in organic semiconductor devices, including solar cells as well as organic light emitting diodes and transistor devices. ${ }^{26-29}$ The high electron affinity of CPEs can provide excellent energy alignment and facilitate electron transfer and collection at the cathodes of OSCs. ${ }^{30,31}$ Cao and coworkers, for example, have recently reported a series of tunable n-type CPEs with counterions which allow interfacial engineering of the cathode band structure. This interlayer was applied in various polymer solar cells and yielded up to $10.5 \%$ efficiency using an active layer comprising NT812 : $\mathrm{PC}_{71} \mathrm{BM}^{32}$

Although CPEs have repeatedly been demonstrated to provide excellent control over the band structure at different interfaces in semiconducting devices, the fundamental mechanisms by which they alter electronic band structures of semiconducting devices aren't completely understood. Some general class of materials have proven to be effective, (such as polyfluorenes with pendant quaternized ammonium ions), however, the reasons why these materials work especially well remains somewhat of a mystery, and it still isn't possible to predict what effects new ionic materials will have on semiconductor band structures.

Non-conjugated polyelectrolytes (NPEs, also known simply as polyelectrolytes), do not possess the conjugated polymer backbones which are present in CPEs; this greatly reduces the amount of synthetic effort required to prepare them compared to CPEs. Additionally, NPEs make an excellent platform to study the purely ionic effects of interfacial electrolytic materials without introducing an additional semiconducting material (i.e. the conjugated backbone in CPEs) which may convolute the effects of the ionic functionalities.

NPEs are also generally water soluble and can be deposited from aqueous solutions, making them an environmentally friendly approach to control the work function (WF) of electrode such as ITO. ${ }^{33}$ NPEs such as polyethyleneimine (PEI) and polyallylamine (PAA) have been used as interfacial layers on ITO, creating a polarized surface with a reduced WF and allowing ITO to function effectively as a cathode. In this context, NPEs are able to align the lowest unoccupied molecular orbital band (LUMO) level of the active layer with the Fermi level at the cathode to create an ohmic contact which allows efficient extraction of electrons from the photoactive layer. An efficiency of $6.3 \%$ was reported for inverted devices based on a PTB7 active layer, comparable to results using CPE interfacial layers. ${ }^{36}$ Although it appears that the ionic character of NPEs allows them to have similar effects on the band structure of semiconducting devices as CPEs, the range of NPE materials studied so far has remained very limited and further studies are necessary to understand how different ionic functionalities in NPEs affect the band structure of semiconducting devices.

In this contribution, we've prepared a series of NPEs with different counterions to investigate the effect of counter-ion identity on the band structure and properties of semiconducting devices including solar cells based on P3HT and PTB7 active layers as well as transistor devices based on Indium
Zinc Oxide (IZO). The influence of NPEs on the WF of electrodes and band structures of semiconducting layers was investigated by ultraviolet photoelectron spectroscopy (UPS). Finally, NPEs were introduced as interfacial layers between the ITO substrate (cathode) and the photoactive layer in solar cell devices, and between the transport channel and source - drain electrodes to investigate the influence of the anion identity on solar cell and transistor parameters.

\section{Experimental details}

Non-conjugated polyelectrolytes $\left(\mathrm{PEIH}^{+} \mathrm{Br}^{-}, \quad \mathrm{PEIH}^{+} \mathrm{I}^{-}\right.$, $\mathrm{PEIH}^{+} \mathrm{BIm}_{4}{ }^{-}$) were synthesized following previously reported procedures as described in the ESI (Fig. S1 and S2 $\dagger$ ). ${ }^{34,35}$ Patterned ITO substrates $\left(1.5 \times 1.5 \mathrm{~cm}, 7 \Omega \mathrm{sq}^{-1}\right)$ were cleaned by ultra-sonication in deionized water, acetone and isopropanol (IPA) for 20 minutes each. The cleaned ITO substrates were then treated with ozone using a UV-ozone cleaner to remove trace organic residues remaining on the surface, followed by drying in an oven at $100{ }^{\circ} \mathrm{C}$ immediately prior to use. NPE layers were deposited by spin coating NPE solutions based on the PEI backbone with variable concentration $(0.1-0.005 \%)$. The counterions included bromide $\left(\mathrm{PEIH}^{+} \mathrm{Br}^{-}\right)$, iodide $\left(\mathrm{PEIH}^{+} \mathrm{I}^{-}\right)$, and tetrakis(imidazolyl) borate $\left(\mathrm{PEIH}^{+} \mathrm{BIm}_{4}{ }^{-}\right)$; these layers were deposited by spin-coating solutions in methanol at $2000 \mathrm{rpm}$.

Active layers comprised BHJ mixtures of PTB7 (1-Material) and $\mathrm{PC}_{71} \mathrm{BM}$ (Aldrich) and were used as received from the vendors. Active layers were deposited by spin coating a mixed solution of PTB7 : PC $_{71} \mathrm{BM}(1: 1.5)$ in chlorobenzene (concentration of $10 \mathrm{mg} \mathrm{mL}^{-1}$ ) containing $3 \%$ DIO additive at $1300 \mathrm{rpm}$ for $60 \mathrm{~s}$ on top of the NPE treated ITO substrates to obtain BHJ films with thicknesses of approximately $80 \mathrm{~nm}$. Samples were then brought under vacuum (about $10^{-7}$ Torr), and $\mathrm{MoO}_{3}(8$ $\mathrm{nm})$ and $\mathrm{Ag}$ electrodes $(100 \mathrm{~nm})$ were deposited on top of the BHJ layers by thermal evaporation.

Current density-voltage $(J-V)$ measurements were collected using a Keithley 2635 source measure unit, carried out inside a nitrogen filled glove-box using a high quality optical fiber to guide the light from a xenon arc lamp to the solar cell devices. Solar cell devices were illuminated with an intensity of $100 \mathrm{~mW}$ $\mathrm{cm}^{-2}$, which was calibrated using a standard silicon reference cell immediately prior to testing. External quantum efficiency (EQE) measurements were carried out using a QEX7 system manufactured by PV Measurements, Inc.

For field effect transistors (FETs) $10 \mathrm{~nm}$ IZO channel layers were deposited by sputtering onto cleaned $\mathrm{Si} / \mathrm{SiO}_{2}$ substrates. The films were annealed at $250{ }^{\circ} \mathrm{C}$ for an hour in air. $\mathrm{PEIH}^{+} \mathrm{BIm}_{4}{ }^{-}$solutions were prepared in methanol at different concentrations $(0.005 \%$, $0.01 \%, 0.05 \%$ and $0.1 \%$ ) to control the film thickness. $\mathrm{PEIH}^{+} \mathrm{BIm}_{4}{ }^{-}$ films were spin coated at a spin rate of $2000 \mathrm{rpm}$ for $60 \mathrm{~s}$. Finally, about $70 \mathrm{~nm}$ thick Au source and drain electrodes were deposited under vacuum by thermal evaporation on top of the channel layerusing a shadow mask. The channel length $(L)$ and width $(W)$ were 40 and $2500 \mu \mathrm{m}$, respectively. Electrical characterization of transistor devices was performed in an $\mathrm{N}_{2}$-atmosphere glove box using a Keithley SCS-4200 semiconductor parameter analyser. For each condition, 40 devices were fabricated and tested. Average 
values are reported with uncertainty intervals $( \pm)$ corresponding to one standard deviations for each parameter measured.

Atomic force microscopy (AFM) images were obtained using a Veeco Multimode microscope operating in tapping mode. Xray photoelectron spectroscopy (XPS) and UPS experiments were carried out using a Thermo Fischer Scientific ESCALAB 250XI.

\section{Results and discussion}

Our primary interest in these NPE materials was to understand their impact on the characteristics and performance of semiconducting devices. To investigate their effect on photovoltaic properties, IOSCs were prepared with NPEs layers deposited at the semiconductor/cathode interface, as depicted in Fig. 1. Fig. 1 shows a schematic device diagram of the IOSC architecture used in this study as well as the chemical structures of the NPEs employed. These NPEs comprise protonated (positively charged) branched PEI backbones (which lack $\pi$-conjugation), and bromide $\left(\mathrm{PEIH}^{+} \mathrm{Br}^{-}\right)$, iodide $\left(\mathrm{PEIH}^{+} \mathrm{I}^{-}\right)$or tetrakis (imidazoly) borate $\left(\mathrm{PEIH}^{+} \mathrm{BIm}_{4}{ }^{-}\right)$counterions.

AFM was used to characterize the surface morphology and roughness of the interlayers; topographic images $(2 \mu \mathrm{m} \times 2 \mu \mathrm{m})$ of each cathode interlayer are shown in Fig. 1b-f. Each sample was fabricated by spin coating NPE films onto ITO substrates using the same conditions used to fabricate solar cell devices. Pristine ITO substrates (Fig. 1b) exhibited homogenous surfaces with a root mean square (RMS) roughness of $1.36 \mathrm{~nm}$. Fig. 1c shows an AFM image of a methanol treated ITO surface. The film showed a low RMS of $1.39 \mathrm{~nm}$, similar to the pristine ITO surface. Fig. 1d shows the topography of a $\mathrm{PEIH}^{+} \mathrm{Br}^{-}(12 \mathrm{~nm})$
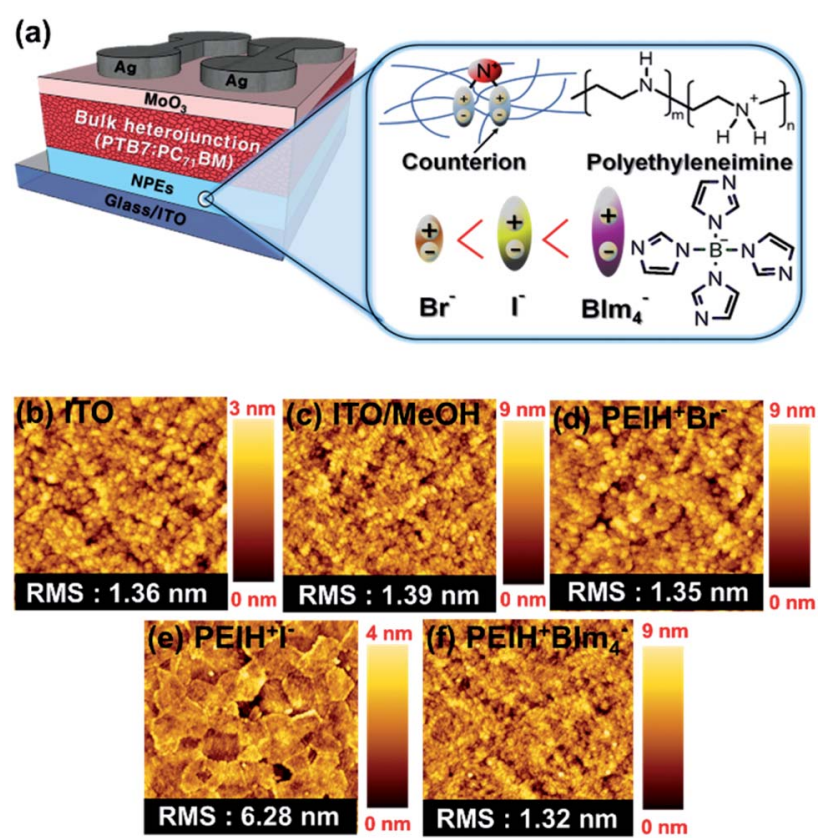

Fig. 1 (a) Device structure and the chemical structures of NPEs used in the devices fabrication. Surface topographic AFM images having size of $(2 \mu \mathrm{m} \times 2 \mu \mathrm{m})$ for (b) ITO, (c) ITO/MeOH treatment, (d) ITO/12 nm $\mathrm{PEIH}^{+} \mathrm{Br}^{-}$, (e) ITO/6.4 nm PEIH ${ }^{+} I^{-}$and (f) ITO/7.1 nm PEIH ${ }^{+} \mathrm{BIm}_{4}{ }^{-}$films.
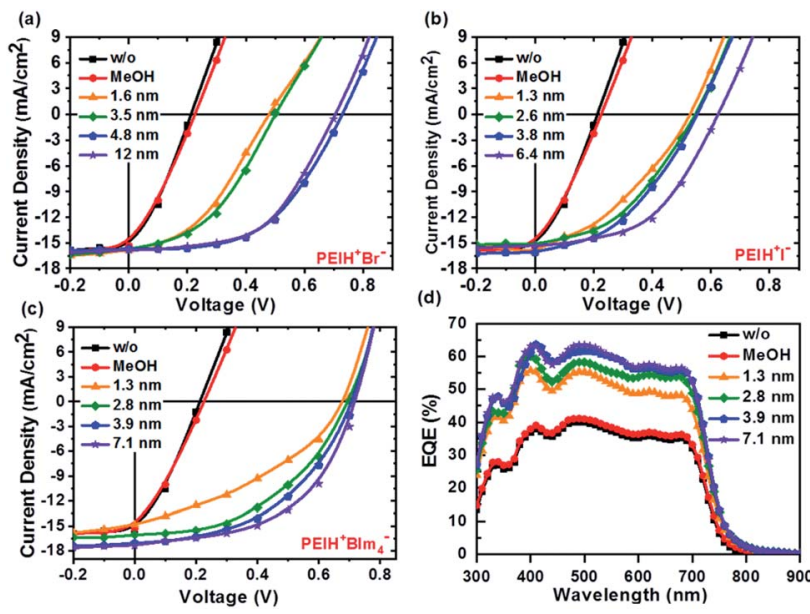

Fig. 2 Current density-voltage curves of PTB7: $\mathrm{PC}_{71} \mathrm{BM}$ solar cells with the NPE ETL layers (a) $\mathrm{PEIH}^{+} \mathrm{Br}^{-}$, (b) $\mathrm{PEIH}^{+} \mathrm{I}^{-}$, (c) $\mathrm{PEIH}^{+} \mathrm{BIm}_{4}^{-}$, and (d) EQE spectra of the devices corresponding to (c).

film deposited on ITO. The RMS roughness of the surface was $1.35 \mathrm{~nm}$ for the $\mathrm{PEIH}^{+} \mathrm{Br}^{-}$layer, indicating increased roughness compared to the pristine ITO substrate. Fig. 1e shows that $\mathrm{PEIH}^{+} \mathrm{I}^{-}(6.4 \mathrm{~nm})$ deposited on ITO comprised large agglomerates, with an RMS roughness of $6.28 \mathrm{~nm}$, which is the roughest surface among the different interlayers. The morphology of a $\mathrm{PEIH}^{+} \mathrm{BIm}_{4}^{-}(7.1 \mathrm{~nm})$ layer deposited on ITO is shown in Fig. 1f. This film exhibited an RMS roughness of $1.41 \mathrm{~nm}$, which was the lowest among the NPE counterions. The surface of the thin film was smooth and showed good morphological characteristics for OPV devices.

Fig. 2 shows the $J-V$ characteristics of inverted BHJ devices with various cathode interfacial layers $\left(\mathrm{PEIH}^{+} \mathrm{Br}^{-}, \mathrm{PEIH}^{+} \mathrm{I}^{-}\right.$, and $\mathrm{PEIH}^{+} \mathrm{BIm}_{4}{ }^{-}$) under AM 1.5G illumination with an intensity of $100 \mathrm{~mW} \mathrm{~cm}{ }^{-2}$. Photovoltaic parameters of these devices are summarized in Table 1. Device data corresponding to poly 3hexyl thiophene active layers can be found in the ESI (Fig. S3 $†$ ). The control device without any interlayer exhibited a low PCE of $1.05 \%$ with a short-circuit current density $\left(U_{\mathrm{sc}}\right)$ of $15.71 \mathrm{~mA}$ $\mathrm{cm}^{-2}$, an open-circuit voltage $\left(V_{\mathrm{OC}}\right)$ of $0.211 \mathrm{~V}$ and a fill factor (FF) of $29.4 \%$, these characteristics indicate that bare ITO is a poor n-type contact. Fig. 2a shows the $J-V$ characteristics of the devices with $\mathrm{PEIH}^{+} \mathrm{Br}^{-}$layer, which under optimal processing conditions exhibited a PCE of 5.96\%, including a $V_{\mathrm{OC}}$ of $0.703 \mathrm{~V}$, a $J_{\mathrm{SC}}$ of $15.70 \mathrm{~mA} \mathrm{~cm} \mathrm{~cm}^{-2}$ and $\mathrm{FF}$ of $54.2 \%$ at a film thickness of $4.8 \mathrm{~nm}$. Fig. $2 \mathrm{~b}$ shows the $J-V$ characteristics of devices using $\mathrm{PEIH}^{+} \mathrm{I}^{-}$. Optimal processing conditions for this NPE constituted relatively thin layers; these devices exhibited a PCE of $4.95 \%$ including a $V_{\mathrm{OC}}$ of $0.635 \mathrm{~V}, J_{\mathrm{SC}}$ of $15.31 \mathrm{~mA} \mathrm{~cm}{ }^{-2}$ and $\mathrm{FF}$ of $51.5 \%$ at a thickness of $6.4 \mathrm{~nm}$.

When $\mathrm{PEIH}^{+} \mathrm{BIm}_{4}{ }^{-}$was used as the interfacial layer, the PCE was observed to increase with increasing interlayer thickness. As shown in Fig. 2c, the $J-V$ characteristics of the device with a $\mathrm{PEIH}^{+} \mathrm{BIm}_{4}{ }^{-}$thickness of $7.1 \mathrm{~nm}$ showed the highest performance, with a significant increase in PCE $(6.77 \%)$ compared to control devices, with a $V_{\mathrm{OC}}$ of $0.710 \mathrm{~V}, J_{\mathrm{SC}}$ of $17.34 \mathrm{~mA} \mathrm{~cm}{ }^{-2}$ and FF of $55.2 \%$. 
Table 1 Summary of device characteristics of PTB7 : PC ${ }_{71}$ BM solar cells with different NPE thicknesses

\begin{tabular}{|c|c|c|c|c|c|c|c|c|}
\hline & & & $J_{\mathrm{SC}}\left(\mathrm{mA} \mathrm{cm}^{-2}\right)$ & $J_{\mathrm{SC}}, \operatorname{EQE}\left(\mathrm{mA} \mathrm{cm}{ }^{-2}\right)$ & $V_{\mathrm{OC}}(\mathrm{V})$ & $\mathrm{FF}(\%)$ & \multicolumn{2}{|l|}{ PCE (\%) } \\
\hline $\mathrm{MeOH}$ treatment & - & - & $15.88 \pm 0.07$ & 12.21 & $0.226 \pm 0.006$ & $31.5 \pm 2.8$ & $0.93 \pm 0.29$ & 1.09 \\
\hline \multirow[t]{2}{*}{$\mathrm{PEIH}^{+} \mathrm{Br}^{-}$} & 0.005 & 1.6 & $15.64 \pm 0.05$ & - & $0.471 \pm 0.009$ & $42.6 \pm 0.8$ & $2.87 \pm 0.17$ & 3.09 \\
\hline & 0.01 & 3.5 & $15.79 \pm 0.09$ & - & $0.497 \pm 0.011$ & $44.2 \pm 0.9$ & $3.12 \pm 0.15$ & 3.45 \\
\hline \multirow[t]{4}{*}{ PEIH $^{+} I^{-}$} & 0.005 & 1.3 & $16.10 \pm 0.05$ & - & $0.523 \pm 0.005$ & $32.4 \pm 2.7$ & $2.45 \pm 0.16$ & 2.69 \\
\hline & 0.01 & 2.6 & $15.25 \pm 0.09$ & - & $0.541 \pm 0.009$ & $38.7 \pm 2.8$ & $3.01 \pm 0.10$ & 3.13 \\
\hline & 0.05 & 3.8 & $16.14 \pm 0.07$ & - & $0.544 \pm 0.006$ & $43.2 \pm 2.8$ & $3.48 \pm 0.27$ & 3.77 \\
\hline & 0.1 & 6.4 & $15.31 \pm 0.52$ & - & $0.635 \pm 0.003$ & $51.5 \pm 2.2$ & $4.72 \pm 0.21$ & 4.95 \\
\hline \multirow[t]{2}{*}{$\mathrm{PEIH}^{+} \mathrm{BIm}_{4}^{-}$} & 0.005 & 1.3 & $14.84 \pm 0.11$ & 14.23 & $0.697 \pm 0.002$ & $31.6 \pm 1.0$ & $3.02 \pm 0.11$ & 3.2 \\
\hline & 0.01 & 2.8 & $16.03 \pm 0.05$ & 15.89 & $0.706 \pm 0.006$ & $46.7 \pm 0.7$ & $5.11 \pm 0.09$ & 5.2 \\
\hline
\end{tabular}

When the NPE thickness became sufficiently thick (>10 nm), "quantum tunneling" for electron transfer from the photoactive BHJ layer to the ITO cathode was inhibited due to the wide bandgap and absence of a conjugated backbone in the NPE layer, which causes it to act as an electrical insulator and impose a large energy barrier. ${ }^{37,38} \mathrm{EQE}$ spectra of various devices are shown in Fig. 2d The EQE spectra for all devices show similar spectral features, consistent with the identical active layers used in each device. However, the EQE of the devices with NPE ETLs show similar spectral shape with higher quantum efficiencies throughout the spectra. This is consistent with the

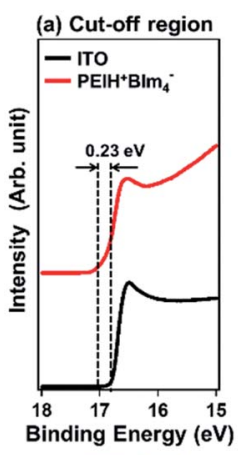

(b)
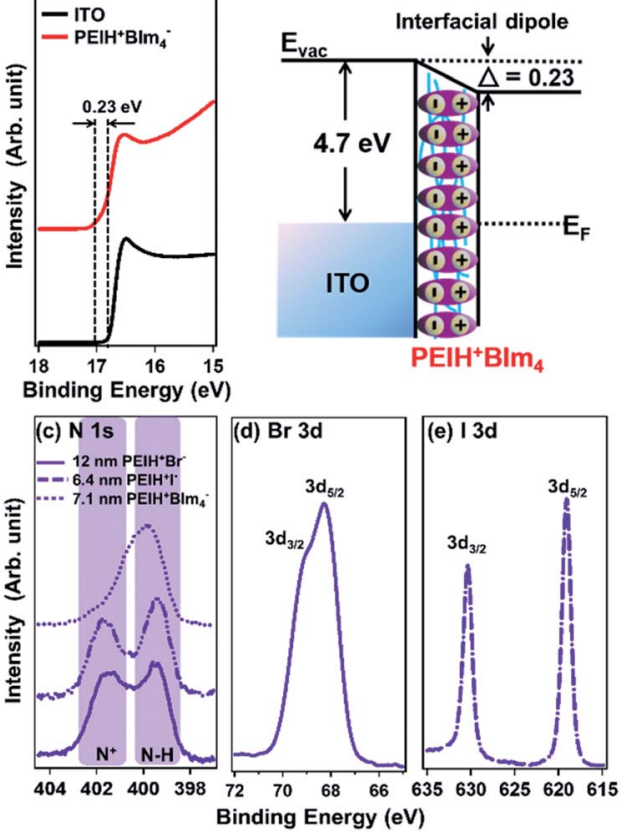

Fig. 3 (a) UPS spectra of ITO (black) and ITO/PEIH ${ }^{+} \mathrm{BIm}_{4}{ }^{-}$film (red), (b) energy level diagram of the IOSCs. The XPS spectra of (c) $\mathrm{N} 1 \mathrm{~s}$ for $\mathrm{PEIH}^{+} \mathrm{Br}^{-}, \mathrm{PEIH}^{+} \mathrm{I}^{-}$, and $\mathrm{PEIH}^{+} \mathrm{BIm}_{4}{ }^{-}$(d) $\mathrm{Br} 3 \mathrm{~d}$ core level of $\mathrm{PEIH}^{+} \mathrm{Br}^{-}$of having thickness $4.8 \mathrm{~nm}$ and (e) I $3 \mathrm{~d}$ core level of $\mathrm{PEIH}^{+} \mathrm{I}^{-}$of having thickness $6.4 \mathrm{~nm}$. larger $J_{\mathrm{SC}}$ observed in devices with NPE layers and the negligible absorption/reflection of the ultra-thin NPE layers. Although devices without NPEs have similar optical properties as the NPE devices, the reduced EQE in this condition is consistent with the lower built-in potential across the active layer, which reduces the efficiency with which charge carriers are extracted..$^{38}$

Since the $V_{\mathrm{OC}}$ of BHJ solar cell is usually determined by the difference in LUMO of acceptor and highest occupied molecular orbital band (HOMO) of the donor, as well as the WF difference between anode and cathode, ${ }^{39,40}$ the increase in $V_{\mathrm{OC}}$ can be attributed to a decrease in the WF of the ITO cathode after NPE deposition. This effective reduction in WF is mediated by an interfacial dipole effect caused by the NPE layer. Upon depositing a thin NPE film, the ionic functionalities in the NPE orient themselves relative to the film surface in such a way that permanent electrical dipole is formed. This surface dipole reduces the energy which is required to remove an electron from the film surface and thus reduces the effective WF, it is an effect which has been well documented. ${ }^{\mathbf{4 1 , 4 2}}$

Additionally, the NPE layer may block back-diffusion of holes, a process which leads to carrier recombination at the cathode in devices without NPE layers. This reduction in effective WF is mediated by an interfacial dipole effect caused by the NPE layers.
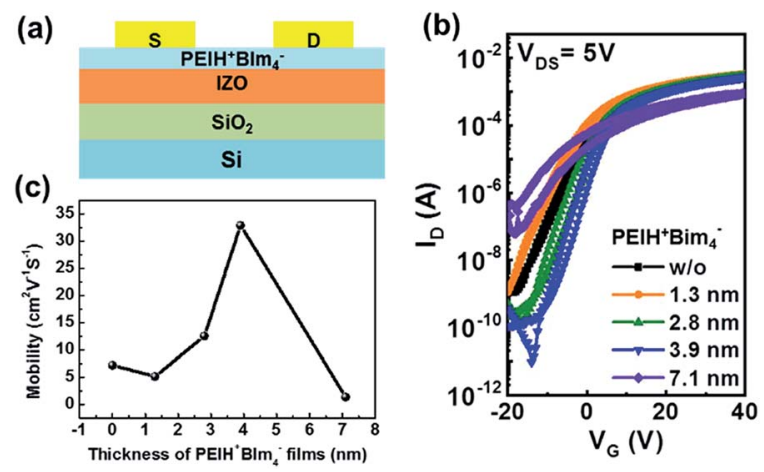

Fig. 4 Transfer characteristics of $n$-type transistors without and with $\mathrm{PEIH}^{+} \mathrm{Blm}_{4}{ }^{-}$as a function of the film thicknesses. $(1.3,2.8,3.9$ and 7.1 $\mathrm{nm})$. 
Table 2 Summary of characteristics of IZO FETs using PEIH ${ }^{+} \mathrm{BIm}_{4}{ }^{-}$interlayers

\begin{tabular}{|c|c|c|c|c|c|}
\hline ETL & Thickness (nm) & $\mu_{\mathrm{e}}\left(\mathrm{cm}^{2} \mathrm{~V}^{-1} \mathrm{~s}^{-1}\right)$ & $I_{\mathrm{on} / \mathrm{off}}$ & $V_{\text {th }}(\mathrm{V})$ & $\mathrm{SS}\left(\mathrm{V} \mathrm{dec}{ }^{-1}\right)$ \\
\hline $\mathrm{w} / \mathrm{o}$ & - & $7.20 \pm 3.84$ & $4.17( \pm 2.09) \times 10^{5}$ & $-4.38( \pm 1.34)$ & $3.46 \pm 0.31$ \\
\hline \multirow{3}{*}{$\mathrm{PEIH}^{+} \mathrm{BIm}_{4}^{-}$} & 1.3 & $5.12 \pm 2.34$ & $4.15( \pm 2.01) \times 10^{5}$ & $-6.10( \pm 0.92)$ & $3.35 \pm 0.24$ \\
\hline & 3.9 & $32.9 \pm 0.93$ & $8.29( \pm 3.10) \times 10^{7}$ & $-4.29( \pm 0.52)$ & $2.61 \pm 0.21$ \\
\hline & 7.1 & $1.33 \pm 1.34$ & $8.48( \pm 2.31) \times 10^{6}$ & $-6.80( \pm 1.25)$ & $5.87 \pm 0.45$ \\
\hline
\end{tabular}

Upon depositing thin NPE films, the ionic functionalities in the NPEs orient themselves relative to the film surface in such a way that permanent electric dipoles are formed. This surface dipole reduces the energy which is required to remove an electron from the film surface and thus reduces the effective WF, an effect which has been well documented. ${ }^{33,36}$

The electronic structures of the interlayers were further investigated by UPS. Fig. 3a shows the secondary electron cutoff regions of photoelectron spectra of various interlayers on ITO substrates. The secondary electron cut-off allows accurate determination of the WF of interlayers; by measuring the shift in the edge of these spectra, relative to the substrate (ITO) it is possible to accurately quantify changes in WF and the magnitude of the interfacial dipole effect caused by each interlayer. Our UPS measurements indicate a WF for pristine ITO to be $4.70 \mathrm{eV}$, which decreased to $4.47 \mathrm{eV}$ after the application of a $\mathrm{PEIH}^{+} \mathrm{BIm}_{4}{ }^{-}$ETL, indicating that the ETL facilitated electron extraction relative to the pristine film, with a corresponding interfacial dipole $(\Delta)$ of $0.23 \mathrm{eV}$. It is well-known that the effective WF of electrodes can be adjusted by introducing a thin layer of NPE, due to the formation of interfacial dipoles. ${ }^{43}$ Fig. $3 \mathrm{~b}$ shows a schematic diagram of the interfacial dipole created by a $\mathrm{PEIH}^{+} \mathrm{BIm}_{4}{ }^{-}$, which lowers the WF of the cathode by $0.23 \mathrm{eV}$. Although the magnitude of the dipole is smaller than non-conjugated polyelectrolytes described in previous reports using other active layers, the observed trends in data are the same, showing a decrease in electrode WF and reduced electron injection barrier. ${ }^{34}$ The magnitude of the interfacial dipole and corresponding effects on device performance follow the size of the anion, where the interfacial dipole created by $\mathrm{PEIH}^{+} \mathrm{BIm}_{4}{ }^{-}$as the greatest and decreased for $\mathrm{I}^{-}$while the dipole for $\mathrm{Br}^{-}$was close to zero. This trend is consistent with trends observed by Do et al. using viologen based cationic polyelectrolytes with variously sized anions.

In order to investigate the chemical properties of the different counterions, XPS spectra were collected. Fig. 3c shows the XPS spectra of $\mathrm{PEIH}^{+} \mathrm{Br}^{-}$and $\mathrm{PEIH}^{+} \mathrm{I}^{-}$films and indicate that the $\mathrm{N}$ 1s core level occurs at $403.3 \mathrm{eV}$ in $\mathrm{PEIH}^{+} \mathrm{Br}^{-}$and $\mathrm{PEIH}^{+} \mathrm{I}^{-}$, which is consistent with quaternized $\mathrm{N}^{+}{ }^{44,45}$ Fig. 3d also shows that the $\mathrm{Br} 3 \mathrm{~d}$ emission line at $68.3 \mathrm{eV}$ for the thin $\mathrm{PEIH}^{+} \mathrm{Br}^{-}$film, corresponding to the anionic bonding state of $\mathrm{Br}^{46}$ Also, Fig. 3e shows the I 3d emission lines at $619.2 \mathrm{eV}$ and $630.8 \mathrm{eV}$ comes from the ionic and covalent bond of $\mathrm{PEIH}^{+} \mathrm{I}^{-}$films respectively. XPS was additionally used to calculate film thickness from attenuation of the substrate (Au 4f) signal, detailed data can be found in the ESI (Fig. S5†).
In order to confirm the effect of NPE layer at the interface, we investigated field effect transistor (FET) devices based on IZO which is inorganic n-type semiconductor without and with a variety of thickness of $\mathrm{PEIH}^{+} \mathrm{BIm}_{4}{ }^{-}$layers. (1.3, 2.8, 3.9 and 7.1 $\mathrm{nm}$ ) Fig. 4 shows the transfer characteristics of n-type FETs. FET performance of data is summarized in Table 2 and output characteristics are in shown in the ESI (Fig. S4 $\dagger$ ). IZO FET without NPE layer exhibited the electron mobility $\left(\mu_{\mathrm{e}}\right)$ of $7.20 \mathrm{~cm}^{2} \mathrm{~V}^{-1} \mathrm{~s}^{-1}$. When using the thin $\mathrm{PEIH}^{+} \mathrm{BIm}_{4}{ }^{-}$layer $(1.3 \mathrm{~nm})$, the $\mu_{\mathrm{e}}$ was slightly decreased to $5.12 \mathrm{~cm}^{2} \mathrm{~V}^{-1} \mathrm{~s}^{-1}$. The $\mu_{\mathrm{e}} \mathrm{s}$ were gradually increased 12.5 and $32.9 \mathrm{~cm}^{2} \quad \mathrm{~V}^{-1} \mathrm{~s}^{-1}$ for devices using $\mathrm{PEIH}^{+} \mathrm{Bim}_{4}{ }^{-}$processed with thicknesses of 2.8 and $3.9 \mathrm{~nm}$, respectively. Specially, in case of using $3.9 \mathrm{~nm}$-thick NPE layer, IZO FET show the optimized $\mu_{\mathrm{e}}$ of $32.9 \mathrm{~cm}^{2} \mathrm{~V}^{-1} \mathrm{~s}^{-1}$ with high onoff ratio $\left(I_{\text {on/off }}\right)$ of $\sim 10^{8}$. While, too thicker $\mathrm{PEIH}^{+} \mathrm{Bim}_{4}{ }^{-}$layer such as $7.1 \mathrm{~nm}$ led to the low $\mu_{\mathrm{e}}$ of $1.33 \mathrm{~cm}^{2} \mathrm{~V}^{-1} \mathrm{~s}^{-1}$ and $I_{\text {on/off }}$ of $\sim 10^{3}$.

\section{Conclusions}

We investigated IOSC devices using solution-processed organic interfacial layers and compared their characteristics. All of the NPE cathode interlayers were effectively used with PTB7 : $\mathrm{PC}_{71} \mathrm{BM}$ active layers, demonstrating a universal increase in performance and suggesting broad applicability for this type of interlayer.

NPE films were also found to improve the performance of thin-film transistor devices via a decrease in the WF of the source and drain electrodes. UPS of $\mathrm{PEIH}^{+} \mathrm{BIm}_{4}{ }^{-}$films confirmed a decrease in WF as a result of deposition on the ITO interface. The observed interfacial dipole and change in Fermi energy are consistent with n-type doping at the interface.

The RMS roughness values of $\mathrm{PEIH}^{+} \mathrm{BIm}_{4}{ }^{-}, \mathrm{PEIH}^{+} \mathrm{Br}^{-}$and $\mathrm{PEIH}^{+} \mathrm{I}^{-}$films were found to be $1.41,3.35$ and $6.28 \mathrm{~nm}$ respectively. Such modification of film morphologies can affect the performance of OSCs; particularly, the $\mathrm{PEIH}^{+} \mathrm{I}^{-}$films are fairly rough for application in OPV devices, and the decreased RMS roughness value upon application of the NPE layers corresponds well with the improved device performance.

These results demonstrate that solution-processed, IOSCs can be success-fully realized using a variety of organic cathode interlayers, and that each interlayer has unique properties which may be optimal for specific applications or active materials.

\section{Conflicts of interest}

There are no conflicts to declare. 


\section{Acknowledgements}

This research was supported by the National Research Foundation of Korea (2017R1C1B1010627 and 2017R1A2B2012971) and through the Kyung Hee University Research Equipment Support Project (KHU-20181297) This work was supported by Busan Institute of Science and Technology Evaluation and Planning (BISTEP) grant (2019 Busan Open Lab. Program) funded by the Korea government (Ministry of Trade, Industry 5 and Energy) and Busan metropolitan city. This research was also supported by the National Research Foundation of Korea (NRF) Grant funded by the Ministry of Science and ICT for FirstMover Program for Accelerating Disruptive Technology Development (NRF-2018M3C1B9088457).

\section{Notes and references}

1 L. Lu, T. Zheng, Q. Wu, A. M. Schneider, D. Zhao and L. Yu, Chem. Rev., 2015, 115, 12666-12731.

2 M. Kaltenbrunner, M. S. White, E. D. Głowacki, T. Sekitani, T. Someya, N. S. Sariciftci and S. Bauer, Nat. Commun., 2012, 3, 770.

3 X. Ouyang, R. Peng, L. Ai, X. Zhang and Z. Ge, Nat. Photonics, 2015, 9, 520.

4 R. R. Søndergaard, M. Hösel and F. C. Krebs, J. Polym. Sci., Part B: Polym. Phys., 2013, 51, 16-34.

5 A. J. Nozik, M. C. Beard, J. M. Luther, M. Law, R. J. Ellingson and J. C. Johnson, Chem. Rev., 2010, 110, 6873-6890.

6 H. Youn, H. J. Park and L. J. Guo, Small, 2015, 11, 2228-2246.

7 Z. He, C. Zhong, S. Su, M. Xu, H. Wu and Y. Cao, Nat. Photonics, 2012, 6, 591.

8 B. Kan, Q. Zhang, M. Li, X. Wan, W. Ni, G. Long, Y. Wang, X. Yang, H. Feng and Y. Chen, J. Am. Chem. Soc., 2014, 136, 15529-15532.

9 Y. Liu, J. Zhao, Z. Li, C. Mu, W. Ma, H. Hu, K. Jiang, H. Lin, H. Ade and H. Yan, Nat. Commun., 2014, 5, 5293.

10 A. Yella, H.-W. Lee, H. N. Tsao, C. Yi, A. K. Chandiran, M. K. Nazeeruddin, E. W.-G. Diau, C.-Y. Yeh, S. M. Zakeeruddin and M. Grätzel, Science, 2011, 334, 629-634.

11 W. Ma, C. Yang, X. Gong, K. Lee and A. J. Heeger, Adv. Funct. Mater., 2005, 15, 1617-1622.

12 Z. Zheng, O. M. Awartani, B. Gautam, D. Liu, Y. Qin, W. Li, A. Bataller, K. Gundogdu, H. Ade and J. Hou, Adv. Mater., 2017, 29, 1604241.

13 P. W. Liang, C. Y. Liao, C. C. Chueh, F. Zuo, S. T. Williams, X. K. Xin, J. Lin and A. K. Y. Jen, Adv. Mater., 2014, 26, 3748-3754.

14 D. Baran, R. S. Ashraf, D. A. Hanifi, M. Abdelsamie, N. Gasparini, J. A. Röhr, S. Holliday, A. Wadsworth, S. Lockett and M. Neophytou, Nat. Mater., 2017, 16, 363.

15 W. Zhao, D. Qian, S. Zhang, S. Li, O. Inganäs, F. Gao and J. Hou, Adv. Mater., 2016, 28, 4734-4739.

16 W. Zhao, S. Li, S. Zhang, X. Liu and J. Hou, Adv. Mater., 2017, 29, 1604059.

17 Q. An, F. Zhang, J. Zhang, W. Tang, Z. Deng and B. Hu, Energy Environ. Sci., 2016, 9, 281-322.

18 X. Che, Y. Li, Y. Qu and S. R. Forrest, Nat. Energy, 2018, 3, 422.
19 T. Kuwabara, K. Yano, T. Yamaguchi, T. Taima, K. Takahashi, D. Son and K. Marumoto, J. Phys. Chem. C, 2015, 119, 5274-5280.

20 V. Vohra, K. Kawashima, T. Kakara, T. Koganezawa, I. Osaka, K. Takimiya and H. Murata, Nat. Photonics, 2015, 9, 403.

21 Y. Sun, J. H. Seo, C. J. Takacs, J. Seifter and A. J. Heeger, Adv. Mater., 2011, 23, 1679-1683.

22 Z.-S. Ma, Q.-K. Wang, C. Li, Y.-Q. Li, D.-D. Zhang, W. Liu, P. Wang and J.-X. Tang, Opt. Commun., 2015, 356, 541-545.

23 O. Örnek, Z. A. Kösemen, S. Öztürk, B. Canımkubey, Ş. Findık, M. Erkovan and A. Kösemen, Surf. Interfaces, 2017, 9, 64-69.

24 M. Thambidurai, J. Y. Kim, H.-j. Song, Y. Ko, N. Muthukumarasamy, D. Velauthapillai, V. W. Bergmann, S. A. Weber and C. Lee, J. Mater. Chem. A, 2014, 2, 11426-11431.

25 S. Cho, K.-D. Kim, J. Heo, J. Y. Lee, G. Cha, B. Y. Seo, Y. D. Kim, Y. S. Kim, S.-Y. Choi and D. C. Lim, Sci. Rep., 2014, 4, 4306.

26 C. V. Hoven, A. Garcia, G. C. Bazan and T. Q. Nguyen, Adv. Mater., 2008, 20, 3793-3810.

27 W. Lee, J. H. Seo and H. Y. Woo, Polymer, 2013, 54, 51045121.

28 A. Duarte, K.-Y. Pu, B. Liu and G. C. Bazan, Chem. Mater., 2010, 23, 501-515.

29 S. Lee, T. L. Nguyen, S. Y. Lee, C. H. Jang, B. R. Lee, E. D. Jung, S. Y. Park, Y. J. Yoon, J. Y. Kim, H. Y. Woo and M. H. Song, Adv. Mater., 2018, 30, 1706034.

30 M. Al Kobaisi, S. V. Bhosale, K. Latham, A. M. Raynor and S. V. Bhosale, Chem. Rev., 2016, 116, 11685-11796.

31 X. Guo, A. Facchetti and T. J. Marks, Chem. Rev., 2014, 114, 8943-9021.

32 Z. Chen, Z. Hu, Z. Wu, X. Liu, Y. Jin, M. Xiao, F. Huang and Y. Cao, J. Mater. Chem. A, 2017, 5, 19447-19455.

33 Y. Zhou, C. Fuentes-Hernandez, J. Shim, J. Meyer, A. J. Giordano, H. Li, P. Winget, T. Papadopoulos, H. Cheun and J. Kim, Science, 2012, 336, 327-332.

34 H. Kang, S. Hong, J. Lee and K. Lee, Adv. Mater., 2012, 24, 3005.

35 H.-B. Kim, Y. J. Yoon, J. Jeong, J. Heo, H. Jang, J. H. Seo, B. Walker and J. Y. Kim, Energy Environ. Sci., 2017, 10, 1950-1957.

36 Y. J. Park, M. J. Cha, Y. J. Yoon, S. Cho, J. Y. Kim, J. H. Seo and B. Walker, Adv. Electron. Mater., 2017, 3, 1700184.

37 C. Han, Y. Cheng, L. Chen, L. Qian, Z. Yang, W. Xue, T. Zhang, Y. Yang and W. Cao, ACS Appl. Mater. Interfaces, 2016, 8, 3301-3307.

38 X. Ouyang, R. Peng, L. Ai, X. Zhang and Z. Ge, Nat. Photonics, 2015, 9, 520.

39 D. Baran, S. Erten-Ela, A. Kratzer, T. Ameri, C. J. Brabec and A. Hirsch, RSC Adv., 2015, 5, 64724.

40 C. J. Brabec, A. Cravino, D. Meissner, N. S. Sariciftci, T. Fromherz, M. T. Rispens, L. Sanchez and J. C. Hummelen, Adv. Funct. Mater., 2001, 11, 374-380.

41 T. T. Do, H. S. Hong, Y. E. Ha, J. Park, Y.-C. Kang and J. H. Kim, ACS Appl. Mater. Interfaces, 2015, 7, 3335-3341.

42 L. Yan, Y. Song, Y. Zhou, B. Song and Y. Li, Org. Electron., 2015, 17, 94-101. 
43 J. H. Seo, R. Yang, J. Z. Brzezinski, B. Walker, G. C. Bazan and T. Q. Nguyen, Adv. Mater., 2009, 21, 1006-1011.

44 R. Hauert, A. Glisenti, S. Metin, J. Goitia, J. Kaufman, P. Van Loosdrecht, A. Kellock, P. Hoffmann, R. White and B. Hermsmeier, Thin Solid Films, 1995, 268, 22-29.
45 L. Köhler, D. Gourdin, R. Sporken, K. Grigorov, J. Riga and R. Caudano, Polym. Int., 1998, 47, 474-478.

46 S. A. Al-Bataineh, L. G. Britcher and H. J. Griesser, Surf. Interface Anal., 2006, 38, 1512-1518. 